\title{
Energy dissipation and antioxidant enzyme system protect photosystem II of sweet sorghum under drought stress
}

\author{
Y.Y. GUO ${ }^{\#}$, S.S. TIAN", S.S. LIU, W.Q. WANG, and N. SUI \\ Shandong Provincial Key Laboratory of Plant Stress, College of Life Science, Shandong Normal University, \\ Jinan, 250014, China
}

\begin{abstract}
The effect of drought stress on energy dissipation and antioxidant enzyme system in two sweet sorghum inbred lines (M-81E and Roma) was investigated. Results showed that the germination indicator increased more in M-81E than that in Roma under rehydration. Under drought stress, both the maximal photochemical efficiency of PSII $\left(\mathrm{F}_{\mathrm{v}} / \mathrm{F}_{\mathrm{m}}\right)$ and oxidoreductive activity $\left(\Delta \mathrm{I} / \mathrm{I}_{0}\right)$ of Roma decreased more than those in M-81E. Relative to $\mathrm{F}_{\mathrm{v}} / \mathrm{F}_{\mathrm{m}}$, the $\Delta \mathrm{I} / \mathrm{I}_{0}$ decreased markedly, which indicated that PSI was more sensitive to drought stress than PSII. Increases in the reduction state of $\mathrm{Q}_{\mathrm{A}}$ $\left(1-q_{p}\right)$, nonphotochemical quenching (NPQ) and minimal fluorescence yield of the dark-adapted state $\left(F_{0}\right)$ were greater in Roma than those in M-81E; meanwhile, the $\mathrm{H}_{2} \mathrm{O}_{2}$ content was lower in M-81E than that in Roma. Our results suggested that the photoinhibition might be related to the accumulation of reactive oxygen species (ROS). The antioxidant enzyme system and energy dissipation of M-81E could respectively increase drought tolerance by eliminating ROS and excess energy more efficiently than that of Roma.
\end{abstract}

Additional key words: antioxidant enzymes; chlorophyll fluorescence; environmental stress; sorghum bicolor; water.

\section{Introduction}

Sweet sorghum (Sorghum bicolor L. Moench) is a highyielding species; it is considered to have potential as an energy crop either for ethanol production obtained by fermentation of stalk sugar or for second generation biofuel acquired from the lignocellulosic biomass (Ballesteros et al. 2004). Sweet sorghum is primarily grown to produce sugar for syrup and is normally used as animal feed (Almodares et al. 2009). It is the fifth most important cereal crop in the world after wheat, rice, corn, and barley (Awika et al. 2004). Among widely grown crop species, sweet sorghum possesses the greatest drought tolerance (Rooney et al. 2007); it is able to survive in water-limited environments owing to a variety of anatomical, morphological, and physiological features
(Jordan et al. 1983). The breeding of crop cultivars with enhanced drought tolerance is currently one of the biggest challenges for plant sciences (Ogbaga et al. 2014).

Drought is one of the important environmental stress factors limiting plant growth and crop yield (Terzi and Kadioglu 2006). According to available data, approximately $45 \%$ of the world's agricultural lands are prone to frequent drought, and $38 \%$ of the world's population resides in such areas (Ashraf and Foolad 2007). Unusual dry weather affects germination, growth rate of seedlings, and increases sensitivity of cell elongation to damages induced under stress conditions (Taylor et al. 1982, Delachiave and Pinho 2003, Hamayun et al. 2010). It is evident that physiological responses of plants to drought

Received 2 June 2016, accepted 24 April 2017, published as online-first 13 June 2017.

${ }^{+}$Corresponding author; e-mail: suina800101@,163.com

Abbreviations: APX - ascorbate peroxidase; AsA - ascorbic acid; Chl - chlorophyll; CAT - catalase; DM - dry mass; ETC - electron transport chain; $F_{0}$ - minimal fluorescence yield of the dark-adapted state; FM - fresh mass; $F_{m}$ - maximal fluorescence yield of the dark-adapted state; $F_{\mathrm{m}}{ }^{\prime}$ - maximal fluorescence yield of the light-adapted state; $F_{\mathrm{s}}$ - steady-state fluorescence yield; $F_{\mathrm{v}}$ - variable fluorescence; $\mathrm{F}_{\mathrm{v}} / \mathrm{F}_{\mathrm{m}}$ - maximal quantum yield of PSII photochemistry; MDA - malondialdehyde; NPQ - nonphotochemical quenching; $\mathrm{q}_{\mathrm{p}}$ - photochemical quenching coefficient; ROS - reactive oxygen species; SOD - superoxide dismutase; $\Phi_{\mathrm{PSII}}$ - effective quantum yield of PSII photochemistry.

Acknowledgements: We are grateful for financial support from the NSFC (National Natural Science Research Foundation of China) (31300205), Natural Science Research Foundation of Shandong (ZR2013CQ009), the Science and Technology Development Projects of Shandong Province (2014GNC113005), the Opening Foundation of the State Key Laboratory of Crop Biology, China (2015KF01), the Opening Foundation of Shandong Provincial Key Laboratory of Crop Genetic Improvement, Ecology and Physiology, and the Program for Scientific research innovation team in colleges and universities of Shandong Province.

\# These authors contributed equally to this work. 
stress are extremely complicated and vary among plant species, along with the degree and duration of drought exposure (Evans et al. 1990). Drought-induced osmotic stress limits the availability of water to plant cells, which in turn affects the physiology of plants (Anjum et al. 2011). Drought stress acts by decreasing the germination rate and seedling growth rate (Delachiave and Pinho 2003). In pot marigold and tuberose plants, germination rate, seed vigor, seedling length, and dry mass all decrease with increasing drought stress (Burnett et al. 2005, Zavariyan et al. 2015). The adverse effect of water shortage on germination and seedling growth has been well reported in different crops, such as corn (Mohammadkhani and Heidari 2008, Farsiani and Ghobadi 2009, Khayatnezhad et al. 2010, Beiragi et al. 2011), wheat (Dhanda et al. 2004, Jajarmi 2009), sorghum (Gill et al. 2002), and sunflower (Ahmad et al. 2009).

Mannitol is a type of nontoxic plant tissue compatible solute which can be used to absorb fluids in plant tissues in order to study the physiology of water stress response, and is considered better at eliciting drought stress than polyethylene glycol (PEG) 6000. A previous study showed that inhibitory effects of mannitol were much lower than those of PEG 6000 (Slama et al. 2007). Adverse effects of PEG on plant development are related to inhibitory effects on root oxygen availability and/or to the presence of phytotoxic contaminants, such as heavy metal ions (Plaut and Federman 1985). Since mannitol is a macromolecular osmotic regulation substance, which that cannot pass through the cell wall, it is an ideal material to simulate soil drought.

Drought stress usually leads to oxidative stress arising from stomatal closure (Lei et al. 2006, Ozkur et al. 2009), which causes overreduction of the photosynthetic electron transport chain (ETC) (Bacelar et al. 2007, Ahmed et al. 2009) and overproduction of ROS, which results in an increase of oxidative stress (Smirnoff 1993). Stomatal closure can also reduce $\mathrm{CO}_{2}$ availability in chloroplasts (Asada 1999, Fu and Huang 2001). In intact chloroplasts, superoxide radical and the hydrogen peroxide, which are produced by dismutation of superoxide are rapidly scavenged at their production sites and the active oxygen do not inactivate the PSI complex, the stromal enzymes, or

\section{Material and methods}

Plant culture and treatments: Seeds of the two sweet sorghum lines, M-81E and Roma, used in the study were provided by Shandong Academy of Agricultural Sciences. Sweet sorghum is a variant of sorghum (Sorghum bicolor L. Moench). Dry seeds were stored in a refrigerator at $4^{\circ} \mathrm{C}$ before use.

Germination treatment: Full grain sweet sorghum seeds of uniform size and containing no worm holes were selected and disinfected for $15 \mathrm{~min}$ in $0.1 \% \mathrm{HgCl}_{2}$ solution, and then rinsed with distilled water. The seeds of the scavenging system itself. Thermal energy dissipation in the light-harvesting antenna complexes of PSII is measured as nonphotochemical quenching (NPQ), and it protects the photosynthetic apparatus from inactivation and damage caused by excessive excitation energy during drought stress, and thereby improving crop yield (Horton et al. 1994, Golding and Johnson 2003, El-Sharkawy 2016).

Production of ROS involves the photoreduction of molecular oxygen by iron sulphur centers on the PSI acceptor side (Mehler 1951, Li et al. 2003) as well as by phyllosemiquinone (Kozuleva et al. 2011, 2014). Moreover, the plastoquinone pool (PQ-pool) is also shown to be involved in ROS production in photosynthetic electron transport chain (Mubarakshina and Ivanov 2010). An important protective mechanism is the water-water cycle, which refers to the reduction of atmospheric $\mathrm{O}_{2}$ into water in PSI with electrons generated from water in PSII and without a net change of $\mathrm{O}_{2}$; this has been proposed to be an effective protective mechanism under environmental stress (Nakano and Asada 1980, Asada 1999). Superoxide dismutase (SOD) is one of the key enzymes of the waterwater cycle (Sui 2015); it can convert $\mathrm{O}_{2}{ }^{-}$into $\mathrm{H}_{2} \mathrm{O}_{2}$ and $\mathrm{O}_{2}$, and plays a vital role in defending against superoxidederived oxidative stress in plant cells. Ascorbate peroxidase (APX) reduces $\mathrm{H}_{2} \mathrm{O}_{2}$ to water with ascorbic acid (AsA) as a specific electron donor in chloroplasts and is the most important plant peroxidase for $\mathrm{H}_{2} \mathrm{O}_{2}$ detoxification (Kanematsu and Asada 1990, Miyake and Asada 1992, Noctor and Foyer 1998).

Genetic differences in abiotic stress tolerance have been reported in sorghum under field conditions, which can be useful in recognizing genotypes better suited to sowing in semiarid areas (Igartua et al. 1995, Cosentino 1996, Yu et al. 2004). Although some water stress effects upon seed germination have been reported in sweet sorghum (Oliveira and Gomes-Filho 2009), little is known about these effects during initial embryo growth.

In this study, we determined that photoinhibition of sweet sorghum under drought was related to energy dissipation and the antioxidant enzyme system, and we investigated the protective mechanisms of energy dissipation and antioxidant enzymes in PSII.

M-81E and Roma were germinated in 9-cm diameter Petri dishes containing two layers of filter paper moistened with water. There were 15 seeds in each treatment with three replications. Each variety was tested under four concentrations of mannitol, which were $0,200,400$, and $600 \mathrm{mM}$; the corresponding osmotic potentials of solutions were: 0 , $-0.49,-0.99$, and $-1.49 \mathrm{MPa}$, respectively. After $9 \mathrm{~d}$ of mannitol treatments, seeds were allowed to recover for $7 \mathrm{~d}$. The mannitol solutions and water control were replaced daily with the same volumes. Seeds were germinated in a glasshouse under the light condition of 14-h light/10-h 
dark, and light intensity of $150 \mu \mathrm{mol}\left(\right.$ photon) $\mathrm{m}^{-2} \mathrm{~s}^{-1}$. The temperature in the glasshouse was $25^{\circ} \mathrm{C}$ during the day and $20^{\circ} \mathrm{C}$ at night.

Treatment: Sorghum seeds were soaked in water for $10 \mathrm{~h}$. Plants were grown in an artificial climate chamber with a temperature of $28^{\circ} \mathrm{C}$ during the day and $20^{\circ} \mathrm{C}$ at night. The photoperiod was 8-h light/16-h dark, and the light intensity was about $300 \pm 50 \mu \mathrm{mol}$ (photon) $\mathrm{m}^{-2} \mathrm{~s}^{-1}$. The relative humidity was $58-64 \%$ during the day and $48-54 \%$ at night.

Circular plastic pots used for planting were $16 \mathrm{~cm}$ high, had mouth and the bottom diameters of 17 and $9 \mathrm{~cm}$, respectively. Each pot contained washed river sand and seven seeds of a given variety were planted per pot and watered with water during the germination period. Seedlings with two leaves were watered with $1 / 2$ strength Hoagland nutrient solution. Seedlings with three leaves were watered with complete Hoagland nutrient solution until drought stress was performed. The seedlings were thinned to five seedlings per pot at the four-leaf stage, and the remaining plants were grown to eight leaves under natural drought treatment. Before the experimental treatment, the complete Hoagland nutrient solution was poured into the water collection tray. Then plants were exposed to natural condition for $7 \mathrm{~d}$ (the complete Hoagland nutrient solution was no longer added). After $7 \mathrm{~d}$, we estimated the level of drought stress by weighing methods. The sand water content $=($ fresh mass - dry mass)/fresh mass $\times 100 \%$. After 7 -d drought stress, the sand water content reached the level of severe stress (4.2\%). After 7-d drought treatment, plants were then recovered by watering with complete Hoagland nutrient solution for $7 \mathrm{~d}$. Three replicates were performed for each treatment.

Germination rate: Sweet sorghum seed germination was observed every day and the seed germination rate was determined in accordance with the national seed inspection standards. The final germination rate was calculated after $9 \mathrm{~d}$ as follows:

Germination rate $[\%]=$ (germinated seed number/ germinated total number) $\times 100 \%$

Germination potential is the index evaluating seed germination rate and germination uniformity. Germination potential was calculated as follow:

Germination potential $[\%]=($ germinated seed number at germination peak/test seed number $) \times 100 \%$

Germination index (GI) is a measure of plant germination ability and vitality. Germination index was calculated as follow:

$\mathrm{GI}=\mathrm{Gt} / \mathrm{Dt}$

where Gt is the number of seeds germinating within $9 \mathrm{~d}$;
Dt is the number of the germination days.

Increase in germination rate is a measure of plant germination resilience after recovery from drought stress, and was calculated as follow:

Germination increase rate $[\%]=$ (increase in number of seeds germinating/test seed number $) \times 100 \%$.

Shoot and root length were measured after the 9-d postgermination treatment and 7-d recovery period. The shoot and root lengths were measured with a ruler. Three replicates were performed for each treatment.

Chlorophyll (Chl) fluorescence of seedlings was measured using a portable fluorometer (FMS2, Hansatech, King's Lynn, UK) according to the protocol described by van Kooten and Snel (1990). Minimal fluorescence $\left(\mathrm{F}_{0}\right)$ with all PSII reaction centers open was determined with modulated light which was low enough to avoid induction of significant variable fluorescence $\left(\mathrm{F}_{\mathrm{v}}\right)$. Maximal fluorescence $\left(\mathrm{F}_{\mathrm{m}}\right)$ with all reaction centers closed was determined by irradiation of a dark-adapted leaf (15-min darkness) for $0.8 \mathrm{~s}$ with saturating light of $8,000 \mu \mathrm{mol}$ (photon) $\mathrm{m}^{-2} \mathrm{~s}^{-1}$. The leaf was then illuminated by an actinic light of $500 \mu \mathrm{mol}$ (photon) $\mathrm{m}^{-2} \mathrm{~s}^{-1}$. Steady-state fluorescence $\left(\mathrm{F}_{\mathrm{s}}\right)$ was recorded when the leaf reached steady-state photosynthesis (300-s illumination is standard for induction of steady-state fluorescence, $\mathrm{F}_{\mathrm{s}}$ ) (Buschmann et al. 2013). A second treatment with 0.8 -s saturating light of 8,000 $\mu$ mol(photon) $\mathrm{m}^{-2} \mathrm{~s}^{-1}$ was given to determine maximal fluorescence in the light-adapted state $\left(\mathrm{F}_{\mathrm{m}}{ }^{\prime}\right)$. Maximal photochemical efficiency $\left(\mathrm{F}_{\mathrm{v}} / \mathrm{F}_{\mathrm{m}}\right)$ of PSII was expressed as $\mathrm{F}_{\mathrm{v}} / \mathrm{F}_{\mathrm{m}}=\left(\mathrm{F}_{\mathrm{m}}-\mathrm{F}_{0}\right) / \mathrm{F}_{\mathrm{m}}$. Quantum yield of PSII electron transport was determined using $\Phi_{\mathrm{PSII}}=\left(\mathrm{F}_{\mathrm{m}}{ }^{\prime}-\mathrm{F}_{\mathrm{s}}\right) / \mathrm{F}_{\mathrm{m}}{ }^{\prime}$. Nonphotochemical quenching (NPQ) was calculated as $\mathrm{NPQ}=\mathrm{F}_{\mathrm{m}} / \mathrm{F}_{\mathrm{m}}{ }^{\prime}-1$. Photochemical quenching $\left(\mathrm{q}_{\mathrm{p}}\right)$ was calculated as $\mathrm{q}_{\mathrm{p}}=\left(\mathrm{F}_{\mathrm{m}}{ }^{\prime}-\mathrm{F}_{\mathrm{s}}\right) /\left(\mathrm{F}_{\mathrm{m}}-\mathrm{F}_{0}{ }^{\prime}\right)$ according to Schreiber et al. (1994).

Absorbance at $820 \mathrm{~nm}$ : The oxidoreductive activity $\left(\Delta \mathrm{I} / \mathrm{I}_{0}\right)$ was measured at $820 \mathrm{~nm}$ with a Plant Efficiency Analyzer (PEA Senior, Hansatech, King's Lynn, UK) as described by Schansker et al. (2003), and the $\Delta \mathrm{I} / \mathrm{I}_{0}$ was measured in vivo after half an hour dark adaptation of sweet sorghum leaves. The first reliable measuring point for fluorescence change was at $20 \mu \mathrm{s}$, whereas the first measuring point for transmission change was at $400 \mu \mathrm{s}$. The time constant used for the transmission measurements was $100 \mu \mathrm{s}$. The light intensity used for the transmission measurements was $3000 \mu \mathrm{mol}$ (photon) $\mathrm{m}^{-2} \mathrm{~s}^{-1}$, and was produced by four $650 \mathrm{~nm}$ LEDs (light-emitting diodes). The far-red source was a QDDH73520 LED (Quantum Devices Inc., Barneveld, WI, USA) filtered at $720 \pm 5 \mathrm{~nm}$. The modulated $(33.3 \mathrm{kHz})$ far-red measuring light was provided by an OD820 LED (Opto Diode Corp., Newbury Park, CA, USA) and filtered at $830 \pm 20 \mathrm{~nm}$. Command execution, such as turning on and off the LEDs, took 
approximately $250 \mu \mathrm{s}$. Commands for activating the red light and starting the measurement were synchronized to correct for the delay; for the far-red light, there was a $250 \mu$ s delay between turning on the far-red light and initiation of measurement.

Fresh mass (FM) and dry mass (DM) of shoots and roots of seedlings: The plant material was initially cleaned with distilled water. After the water on the plant was absorbed by tissue paper, FM of the shoots and roots were determined. The DM was determined after drying the fresh material at $70^{\circ} \mathrm{C}$ for $4 \mathrm{~d}$. Three replicates were performed for each treatment.

Antioxidant enzyme activity in seedlings: SOD (EC 1.15.1.1) activity was measured as described by Dhindsa et al. (1981). Samples of leaves (0.2 g) were flash frozen in liquid nitrogen to prevent proteolytic activity, followed by grinding with $5 \mathrm{~mL}$ of extraction buffer $(0.1 \mathrm{M}$ phosphate buffer, $\mathrm{pH} 7.5$, containing $0.5 \mathrm{mM}$ EDTA and $1 \mathrm{mM}$ ascorbic acid). The homogenate was centrifuged for $20 \mathrm{~min}$ at $15,000 \times \mathrm{g}$ and the collection volume of enzyme solution was $3 \mathrm{~mL}$. The concentration of soluble proteins in the supernatant was determined using the Bradford assay with bovine serum albumin (BSA) as the standard (Bradford 1976). The activity of SOD was estimated by recording the decrease in optical density of nitroblue tetrazolium (NBT) induced by the enzyme (Dhindsa et al. 1981). The reaction mixture contained $13 \mathrm{mM}$ methionine, $75 \mu \mathrm{M}$ nitroblue tetrazolium chloride, $0.1 \mathrm{mM}$ EDTA, $50 \mathrm{mM}$ phosphate buffer ( $\mathrm{pH} 7.8$ ), $50 \mathrm{mM}$ sodium carbonate, and $0.1 \mathrm{~mL}$ of enzyme solution. The reaction was started by adding $2 \mu \mathrm{M}$ riboflavin. The reaction mixtures were illuminated for $20 \mathrm{~min}$ at $90 \mu \mathrm{mol}$ (photon) $\mathrm{m}^{-2} \mathrm{~s}^{-1}$ (placing the test tubes under two 15-W fluorescent lamps). The control consisted of a complete reaction mixture without enzyme, which gave the maximal color. The reaction was stopped by switching off the light and placing the tubes in the dark. A nonirradiated complete reaction mixture served as a blank. The absorbance at $560 \mathrm{~nm}$ of the reaction mixture was determined by using a UV/Vis spectrophotometer (UV-1601, Shimadzu, Japan). Enzyme activity was calculated as $50 \%$ inhibition expressed in $U$ per $m g$ of total protein.

\section{Results}

\section{Experiments in germination period}

Germination rate during drought stress: The germination rate of the two sweet sorghum lines declined obviously under drought stress. After $200 \mathrm{mM}$ mannitol treatment, germination rate of M-81E and Roma decreased by 7.1 and $9.1 \%$, respectively. The germination rate of M-81E and Roma decreased by 49.9 and $43.2 \%$ after
The activity of APX (EC 1.11.1.11) was determined according to the method of Jimenez et al. (1997) by monitoring the rate of ascorbate oxidation at $290 \mathrm{~nm}$. The reaction mixture contained $50 \mathrm{mM}$ potassium phosphate buffer ( $\mathrm{pH} 7.0$ ), $0.5 \mathrm{mM}$ ascorbate, $0.2 \mathrm{mM} \mathrm{H}_{2} \mathrm{O}_{2}$, and a suitable volume of enzyme extract. Enzyme activity was calculated per $\mathrm{mg}$ of total protein in $\mathrm{U}$, which represents the amount of enzyme needed to oxide $1 \mu \mathrm{mol}$ of AsA in $1 \mathrm{~min}$ at room temperature.

$\mathrm{H}_{2} \mathrm{O}_{2}$ content was measured as described in Sairam and Srivastava (2002) and Ren et al. (2014). Frozen leaf samples $(0.2 \mathrm{~g})$ were homogenized in $3 \mathrm{~mL}$ of acetone. The homogenate was then centrifuged at $10,000 \times g$ for $10 \mathrm{~min}$ at $4^{\circ} \mathrm{C}$. The supernatant was collected and added to $0.3 \mathrm{~mL}$ of a concentrated hydrochloric acid solution (containing $0.1 \mathrm{~mL}$ of $20 \% \mathrm{TiCl}_{4}$ and $0.2 \mathrm{~mL}$ of concentrated ammonia). The mixture was incubated at $25^{\circ} \mathrm{C}$ for $10 \mathrm{~min}$, and then centrifuged at $8,000 \times g$ for $10 \mathrm{~min}$ at $4^{\circ} \mathrm{C}$. The pellet was washed twice with cold acetone, and then $3 \mathrm{~mL}$ of $1 \mathrm{~mol} \mathrm{~L}^{-1} \mathrm{H}_{2} \mathrm{SO}_{4}$ was added. The absorbance of the solution was measured at $410 \mathrm{~nm}(U V-1601$, Shimadzu, Japan), and the amount of $\mathrm{H}_{2} \mathrm{O}_{2}$ was calculated from a standard curve prepared using known concentrations of $\mathrm{H}_{2} \mathrm{O}_{2}$.

Measurement of MDA content: MDA content was measured as described in Peever and Higgins (1989). Frozen leaf samples $(0.2 \mathrm{~g})$ were homogenized in $1 \mathrm{~mL}$ of $0.1 \%(\mathrm{w} / \mathrm{v})$ trichloroacetic acid (TCA). The homogenate was treated with $1 \mathrm{~mL}$ of $0.1 \%(\mathrm{w} / \mathrm{v})$ TCA flush and $2.5 \mathrm{~mL}$ of tertiary butyl alcohol (TBA). The mixture was heated at $90^{\circ} \mathrm{C}$ for $15 \mathrm{~min}$ and then quickly cooled on ice. The contents were centrifuged at 3,000 $\times g$ for $10 \mathrm{~min}$ and the absorbance of the supernatant at 532 and $600 \mathrm{~nm}$ was read (UV-1601, Shimadzu, Japan). The MDA content was calculated using $155 \mathrm{mM}^{-1} \mathrm{~cm}^{-1}$ as the extinction coefficient.

Statistical analysis: All analyses were performed with SPSS Version 16.0 for Windows (SPSS, Chicago, IL, USA). Multiple comparisons were performed between different environmental conditions using Duncan's test at the 0.05 significance level. Figures were drawn by original data analysis and software Sigma Plot 10.0.

$400 \mathrm{mM}$ mannitol treatment, respectively. After $600 \mathrm{mM}$ mannitol treatment, germination rate of $\mathrm{M}-81 \mathrm{E}$ and Roma decreased by 61.8 and $79.6 \%$, respectively (Figs. $1 A, 2 A$ ). Germination recovery of $\mathrm{M}-81 \mathrm{E}$ was better than that of Roma after $7 \mathrm{~d}$ of water restoration; M-81E also had better germination ability than that of Roma following recovery from the high $(600 \mathrm{mM})$ mannitol treatment (Fig. 1B). 

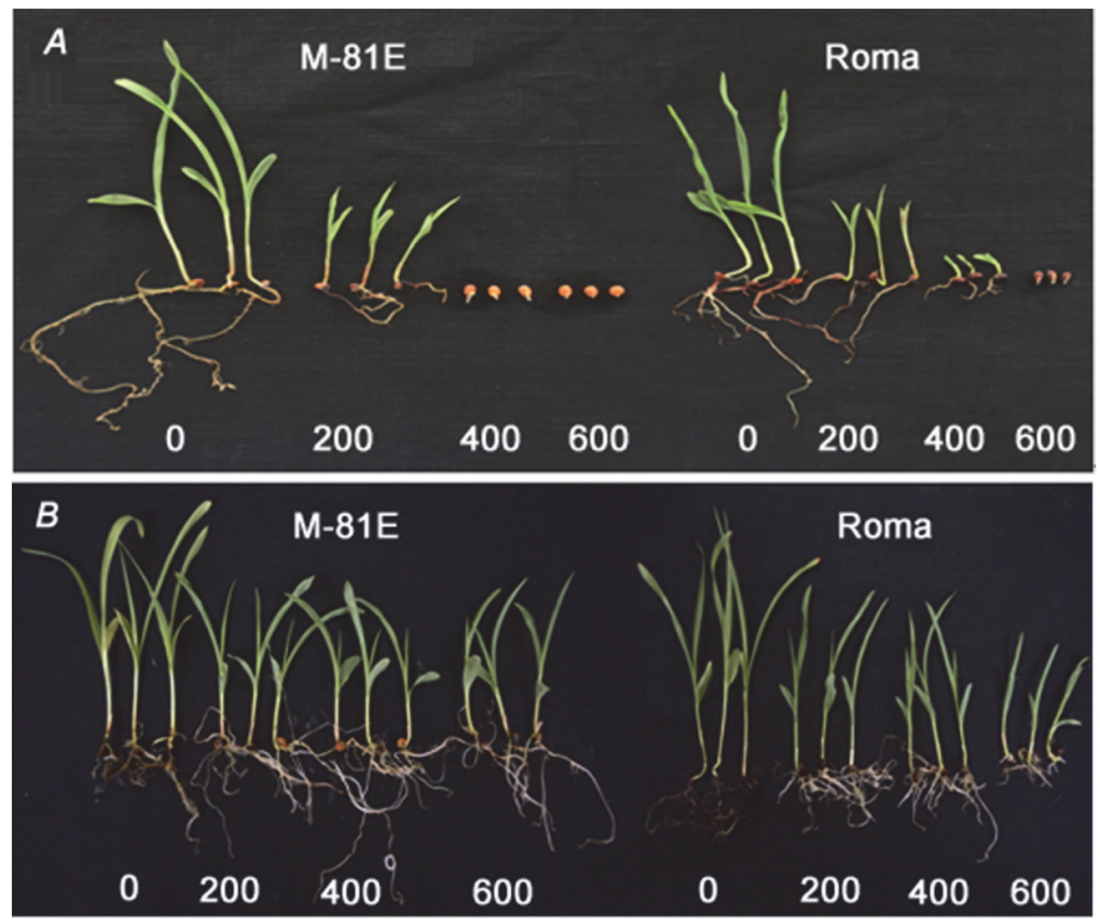

Fig. 1. Germination of two sweet sorghum (Sorghum bicolor L. Moench) lines M-81E and Roma under different mannitol concentration after $9 \mathrm{~d}(A)$ and the 7-d recovery $(B)$.

Germination potential during drought stress: The germination potential of both sweet sorghum lines declined significantly under drought stress. After $200 \mathrm{mM}$ mannitol treatment, germination potential of $\mathrm{M}-81 \mathrm{E}$ and Roma decreased by 28.4 and $37.2 \%$, respectively, while the germination potential of M-81E and Roma decreased by 66.7 and $68.6 \%$ after $400 \mathrm{mM}$ mannitol, and after the $600 \mathrm{mM}$ mannitol treatment, the germination potential of $\mathrm{M}-81 \mathrm{E}$ and Roma decreased by 71.8 and $83.8 \%$, respectively (Fig. $2 B$ ). These results showed that germination rate and uniformity of $\mathrm{M}-81 \mathrm{E}$ were higher than those of Roma.

GI during drought stress: The GI (Gt/Dt) of drought resistance decreased with increasing mannitol concentrations for both inbred sweet sorghum lines. After $200 \mathrm{mM}$ mannitol treatment, the M-81E and Roma germination indices decreased by 26.1 and $32.8 \%$, respectively. The germination indices of M-81E and Roma decreased by 65.8 and $64.0 \%$ after $400 \mathrm{mM}$ mannitol treatment, respectively, while under the stress of $600 \mathrm{mM}$ mannitol, the germination indices of $\mathrm{M}-81 \mathrm{E}$ and Roma decreased respectively by 72.2 and $86.0 \%$ (Fig. $2 C$ ). The results showed that germination ability and vitality of M-81E were higher under 200 and $600 \mathrm{mM}$ mannitol stress than those of Roma. Under $400 \mathrm{mM}$ mannitol treatment, M-81E had a lower germination ability and vitality than that of Roma.

Increase in germination rate following 7-d drought recovery: The germination rate of both sweet sorghum lines increased significantly following seven days of water restoration after mannitol-induced drought stress. The germination rate of M-81E and Roma increased by 13.3 and $11.1 \%$ after recovery from $200 \mathrm{mM}$ mannitol stress, respectively (Fig. 2D). After recovery from $400 \mathrm{mM}$ mannitol treatment, the germination rate of $\mathrm{M}-81 \mathrm{E}$ and Roma increased by 53.3 and $42.2 \%$, respectively. This showed that the recovery of M-81E was better than that of Roma (Fig. 2D).

Shoot and root length during drought stress and recovery in germination: Shoot and root length of both sweet sorghum lines decreased significantly under mannitol-induced drought stress (Fig. 3). Under 200, 400, and $600 \mathrm{mM}$ mannitol, shoot lengths of M-81E decreased by $45.3,97.7$, and $98.8 \%$, respectively, while shoot lengths of Roma decreased by $50.1,88.5$, and $98.9 \%$, respectively (Fig. 3A). Root lengths of M-81E under 200, 400, and $600 \mathrm{mM}$ mannitol treatment decreased by $53.3,95.5$, and $97.7 \%$, respectively, while root lengths in Roma similarly decreased by $52.1,80.7$, and $96.7 \%$, respectively (Fig. $3 B$ ). However, after $7 \mathrm{~d}$ of water restoration, shoot lengths under the 200, 400, and $600 \mathrm{mM}$ mannitol treatments increased by $0.5,30.1$, and 46.0 times in M-81E and 0.3 , 4.3, and 39.3 times in Roma, respectively (Fig. 3C). Root lengths of M-81E under the 200, 400, and $600 \mathrm{mM}$ mannitol treatments underwent respective increases of $0.9,18.5$, and 37.0 times, whereas root lengths of Roma underwent respective increases of $0.7,2.1$, and 13.1 times (Fig. 3D). Our data showed that shoot and root length of $\mathrm{M}-81 \mathrm{E}$ recovered better than those of Roma. Taken 

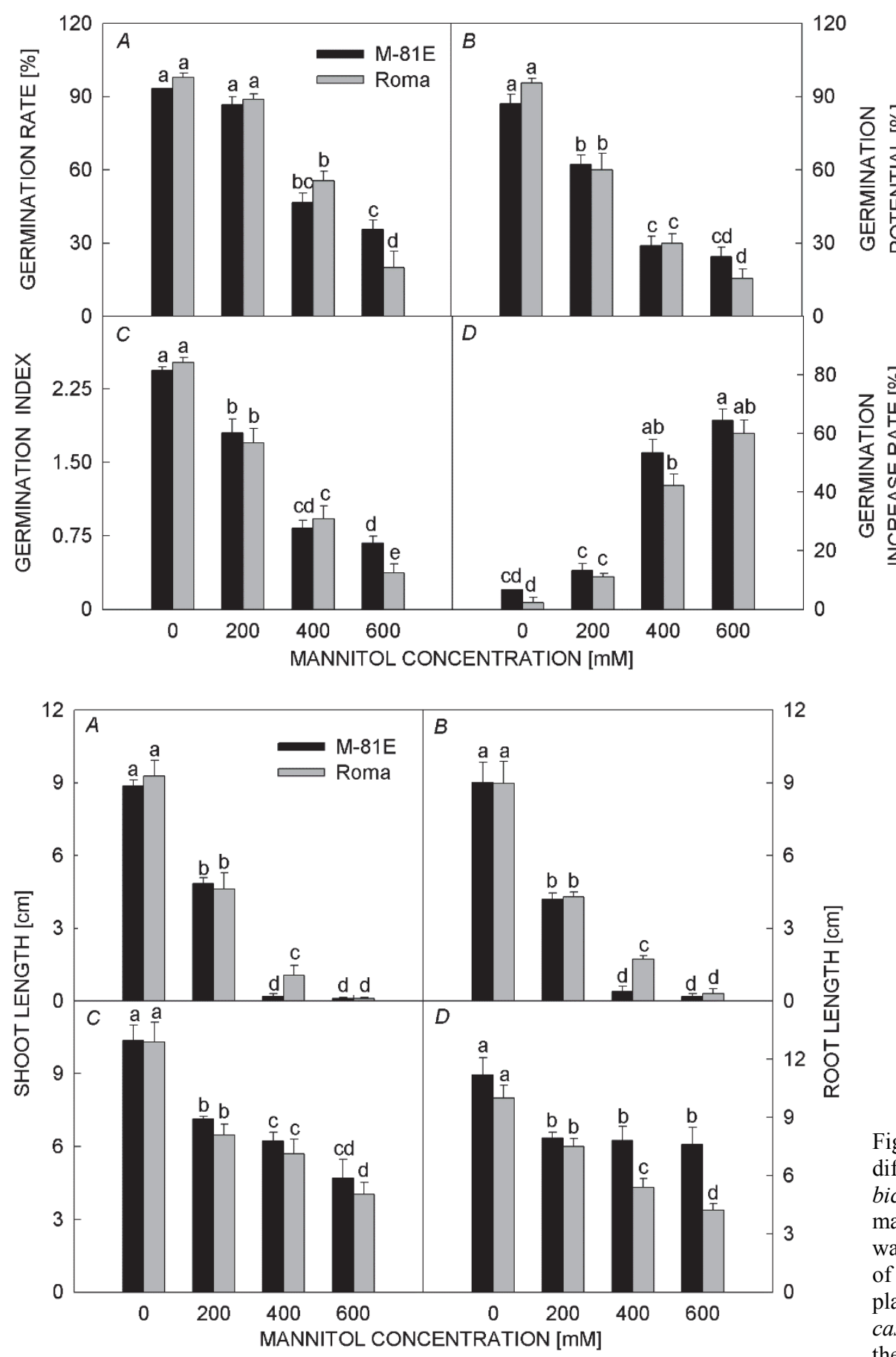

Fig. 2. Germination rate $(A)$, germination potential $(B)$, germination index $(C)$, and germination increase rate $(D)$ of two different sweet sorghum lines (Sorghum bicolor L. Moench) under different mannitol concentration. Each point represents the means $\pm \mathrm{SD}$ of five measurements on each of five plants $(n=5)$. Bars with different lowercase letters show significant differences at the $P<0.05$ level. together, these results showed that M-81E had higher germination rate and recovery ability than those of Roma during the germination period.

\section{Experiments in the seedling period}

Photoinhibition and energy dissipation under natural drought stress and rewatering: Photoinhibition of PSII and PSI was estimated by measuring $F_{v} / F_{m}$ and $\Delta I / I_{0}$, respectively. As shown in Fig. 4, the $F_{v} / F_{m}$ and $\Delta I / I_{0}$ decreased in leaves of both sweet sorghum lines under drought stress; however, Roma showed greater decreases of $F_{v} / F_{m}$ and $\Delta \mathrm{I} / \mathrm{I}_{0}$ than those of M-81E. During drought stress, the respective decreases in $\mathrm{F}_{\mathrm{v}} / \mathrm{F}_{\mathrm{m}}$ of $\mathrm{M}-81 \mathrm{E}$ and Roma were 4.8 and $12.0 \%$; similarly, the $\Delta \mathrm{I} / \mathrm{I}_{0}$ of M-81E and Roma decreased by 18.9 and $36.1 \%$, respectively. The $\Delta \mathrm{I} / \mathrm{I}_{0}$ declined markedly relative to the $\mathrm{F}_{\mathrm{v}} / \mathrm{F}_{\mathrm{m}}$ in the two sweet sorghum lines under drought stress, which indicated that PSI was more sensitive to drought stress than PSII. After 7-d recovery, the $F_{v} / F_{m}$ and $\Delta I / I_{0}$ both returned to normal levels in M-81E, but not in Roma. 


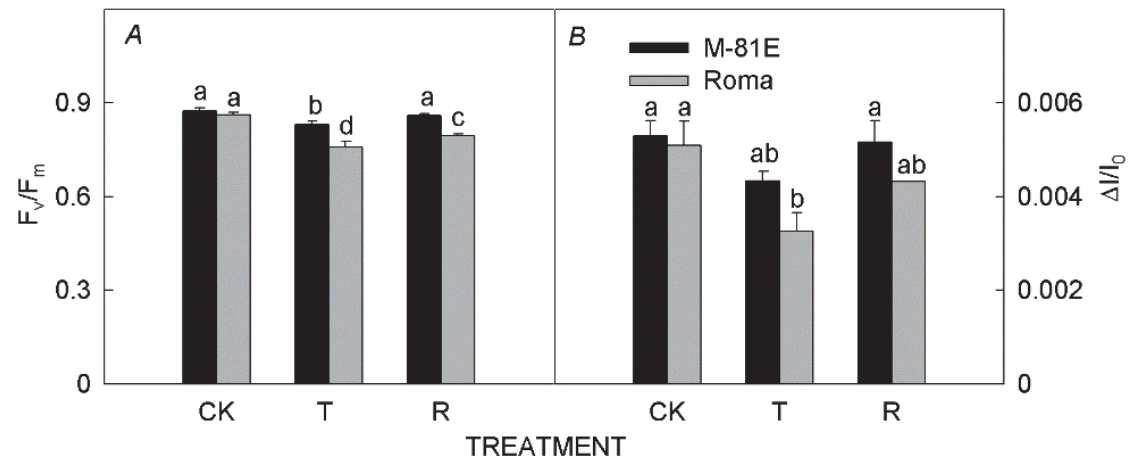

Fig. 4. The maximal photochemical efficiency of PSII $\left(\mathrm{F}_{\mathrm{v}} / \mathrm{F}_{\mathrm{m}}\right)$ and the oxidoreductive activity $\left(\Delta \mathrm{I} / \mathrm{I}_{0}\right)$ in two sweet sorghum (Sorghum bicolor $\mathrm{L}$. Moench) lines under natural drought treatment and after withholding water $(\mathrm{CK}-$ control, $\mathrm{T}$ - natural drought treatment for $7 \mathrm{~d}, \mathrm{R}$ - rewatering for $7 \mathrm{~d}$, the same below). Values are means \pm SD of five measurements for each of five plants $(n=5)$. Bars with different lowercase letters show significant differences at the $P<0.05$ level.

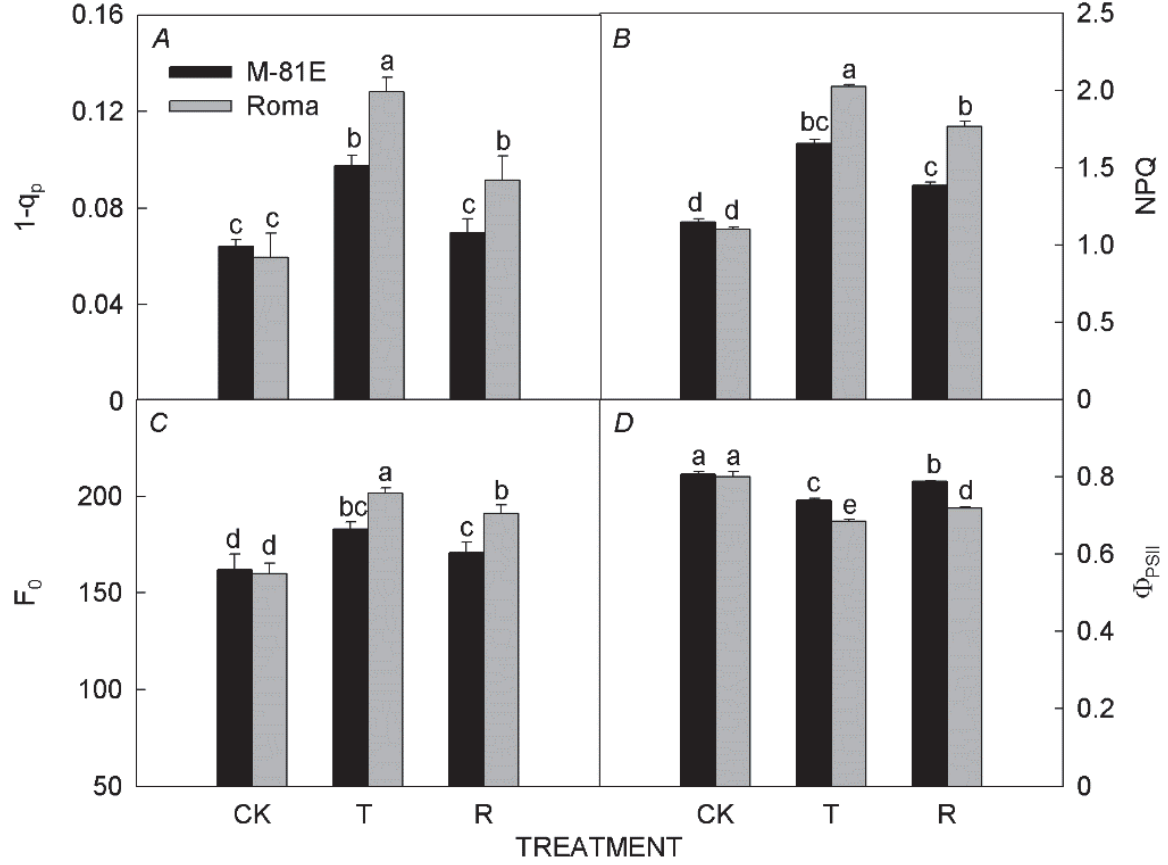

Fig. 5. Changes of the reduction state of $\mathrm{QA}_{\mathrm{A}}\left(1-\mathrm{q}_{\mathrm{p}}\right)$, nonphotochemical quenching (NPQ), minimum fluorescence $\left(\mathrm{F}_{0}\right)$, and $\Phi_{\text {PSII }}$ in two sweet sorghum (Sorghum bicolor L. Moench) lines under natural drought treatment and after withholding water. Values are means \pm SD of five measurements for each of five plants $(n=5)$. Bars with different lowercase letters show significant differences at the $P<0.05$ level.
The $1-\mathrm{q}_{\mathrm{p}}$, NPQ, and $\mathrm{F}_{0}$ in leaves of both sweet sorghum lines increased under drought stress, but to a greater extent in Roma (Fig. 5). The $1-\mathrm{q}_{\mathrm{p}}, \mathrm{NPQ}$, and $\mathrm{F}_{0}$ increased by $51.9,43.8$, and $12.9 \%$ in $\mathrm{M}-81 \mathrm{E}$, and by 114.7, 84.1, and 26.1\% in Roma, respectively. During drought stress, $\Phi_{\text {PSII }}$ of M-81E and Roma decreased by 8.1 and $14.5 \%$, respectively. After $7-\mathrm{d}$ recovery, the $1-\mathrm{q}_{\mathrm{p}}$, $\mathrm{NPQ}$, and $\mathrm{F}_{0}$ of $\mathrm{M}-81 \mathrm{E}$ increased relative to the untreated plants by $8.8,20.4$, and $5.3 \%$, while they increased in Roma by $53.6,60.7$, and $19.4 \%$, respectively. The $\Phi_{\text {PSII }}$ of $\mathrm{M}-81 \mathrm{E}$ and Roma decreased by 2.2 and $10.2 \%$, relative to control group, respectively. These data showed that the recovery of M-81E was better than that of Roma.

\section{Effect of drought stress on FM and DM at the seedling} stage: The degrees of drought tolerance and recovery capability during the seedling stage were better in M-81E than those in Roma. FM and DM of shoots and roots were significantly reduced for both sweet sorghum lines grown under natural drought conditions. Shoot FM of M-81E and Roma under drought stress decreased by 26.9 and $33.6 \%$, respectively (Fig. 6A). Shoot DM of M-81E and Roma under natural drought decreased by 21.7 and $31.8 \%$, respectively (Fig. 6B). Root FM of M-81E and Roma under drought decreased by 21.4 and $52.2 \%$, respectively (Fig. 6C). Root DM of M-81E and Roma under natural drought stress decreased by 16.7 and $52.2 \%$, respectively (Fig. 6D). After rewatering for $7 \mathrm{~d}, \mathrm{FM}$ and DM of shoots and roots increased compared to those of plants under natural drought stress; the respective values for shoot FM of M-81E and Roma increased by 33.2 and 9.6\% (Fig. 6A), respectively; shoot DM of M-81E and Roma increased by 22.2 and $20.0 \%$ (Fig. $6 B$ ), respectively; root FM of M-81E and Roma increased by 23.1 and $15.5 \%$ (Fig. $6 C$ ) and root 


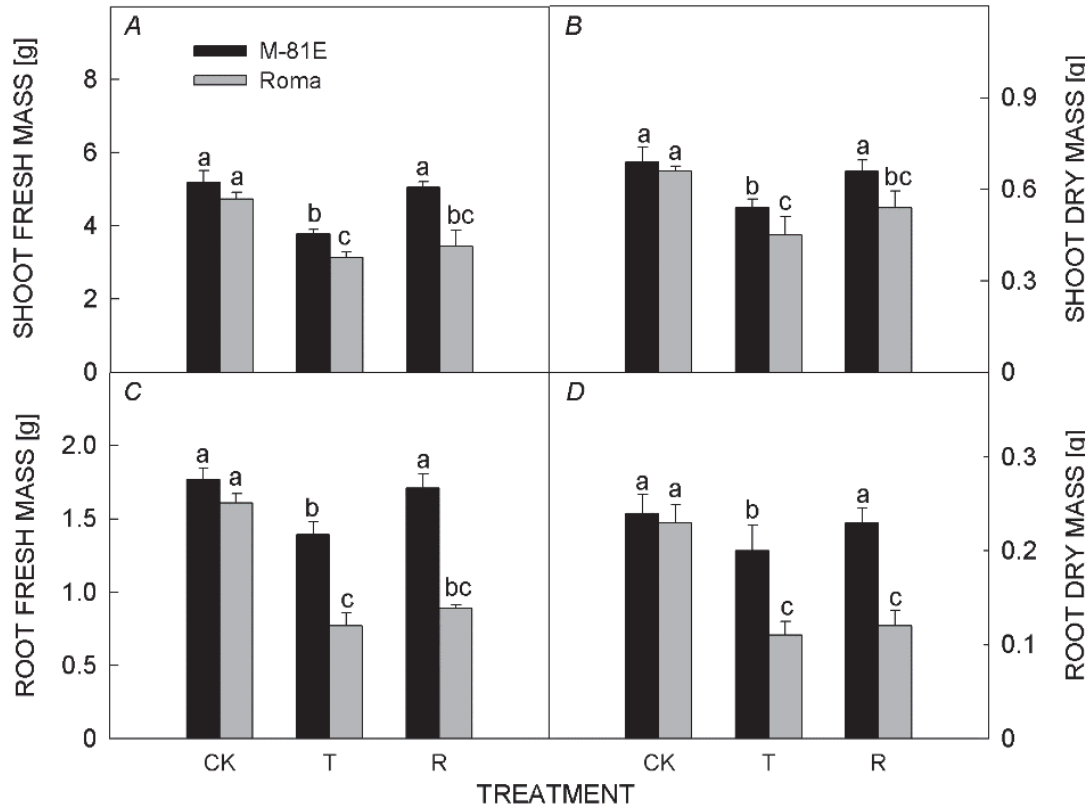

Fig. 6. Shoot and root fresh mass and dry mass in two sweet sorghum (Sorghum bicolor L. Moench) lines under natural drought treatment and after withholding water. Values are means \pm SD of five measurements for each of five plants $(n=5)$ Bars with different lowercase letters show significant differences at the $P<0.05$ level.

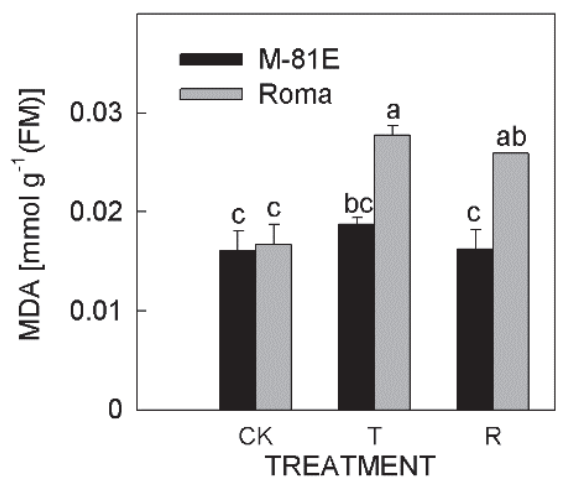

Fig. 7. Changes of MDA content in two sweet sorghum (Sorghum bicolor L. Moench) lines under natural drought stress and rewatering. Values are means $\pm \mathrm{SD}$ of five measurements for each of five plants $(n=5)$. Bars with different lowercase letters show significant differences at the $P<0.05$ level.

DM of M-81E and Roma increased by 15.0 and $9.1 \%$, respectively (Fig. 6D).

Effect of drought stress on antioxidant enzyme activities and $\mathrm{H}_{2} \mathrm{O}_{2}$ content: SOD is one of the key enzymes for scavenging toxic ROS. After 7-d treatment with drought stress, SOD activities of M-81E and Roma increased 1.6 and 1.1 times relative to their respective controls (Fig. 7A). After 7-d rewatering, SOD activity of M-81E and Roma both decreased, but to a greater extent in Roma. These results showed that M-81 had higher antioxidant enzyme activity than that of Roma.

Under drought conditions, APX activity increased in M-81E and Roma by 1.7 and 0.9 times, respectively (Fig. 7B). After 7-d rewatering, APX activity of M-81E recovered to normal levels, while that of Roma recovered slightly relative to the untreated plants. These data showed that M-81E had stronger scavenging ability than Roma.

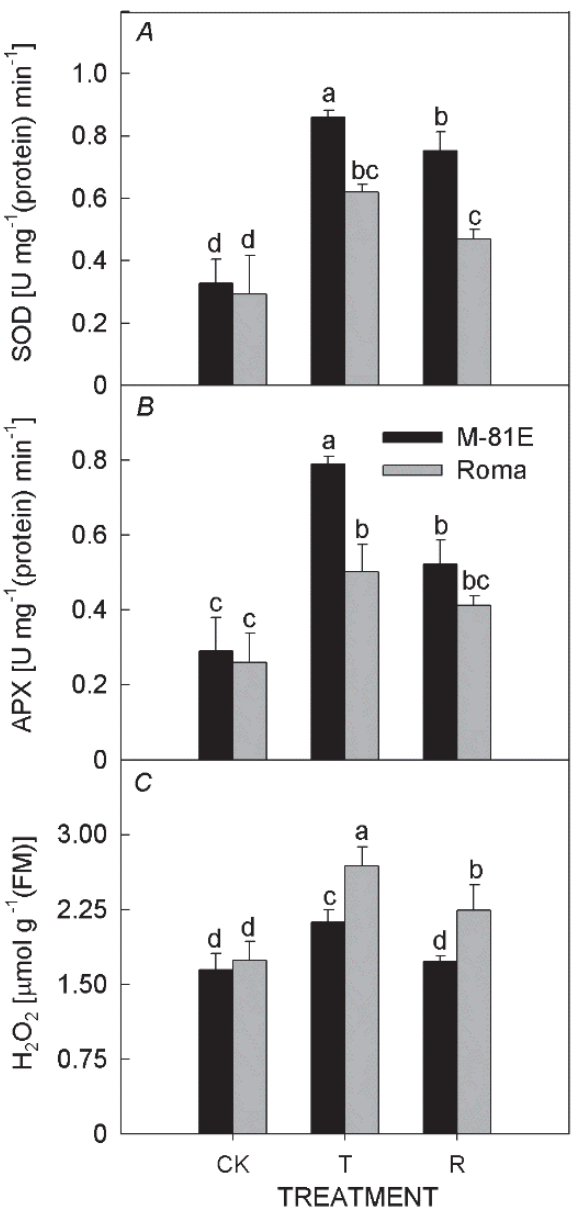

Fig. 8. Changes in the activities of SOD $(A)$ and APX $(B)$, the content of $\mathrm{H}_{2} \mathrm{O}_{2}(C)$ in two sweet sorghum (Sorghum bicolor $\mathrm{L}$. Moench) lines under natural drought treatment and after withholding water. Values are means $\pm \mathrm{SD}$ of five measurements for each of five plants $(n=5)$. Bars with different lowercase letters show significant differences at the $P<0.05$ level. 
Content of $\mathrm{H}_{2} \mathrm{O}_{2}$ increased under drought stress and then decreased after rewatering (Fig. $7 C$ ), and the respective increases of drought-induced $\mathrm{H}_{2} \mathrm{O}_{2}$ content of M-81E and Roma were 28.9 and $54.9 \%$. After 7-d recovery, the $\mathrm{H}_{2} \mathrm{O}_{2}$ of M-81E decreased to normal content, while those of Roma remained higher than in the untreated control.

\section{Discussion}

Drought stress often adversely affects plant growth and development, resulting in severe crop losses. With fresh water resources in shortage, drought has become a serious problem in agricultural production worldwide; thus, the research has focused on understanding the mechanisms of drought stress in plants and the selection of droughtresistant varieties. In this study, we investigated the effects of drought stress on seed germination, the antioxidant enzyme systems, and energy dissipation-mediated photoprotection of two inbred sweet sorghum lines.

Germination rate and germination indices under drought stress are predictive of drought tolerance in sweet sorghum. Germination potential is an index for evaluation of the seed germination rate and germination uniformity; it measures plant germination ability and vitality. Our results showed obvious declines in the germination rate, germination potential, and germination index for the two sweet sorghum lines with increasing mannitol concentrations. The germination rate, germination potential, and germination index of M-81E decreased less than those of Roma under 200 and $600 \mathrm{mM}$ mannitol stress (Fig. 2A-C), which showed the better germination rate and stability for M-81E than that for Roma. The germination rate and germination index of M-81E decreased more than those of Roma under $400 \mathrm{mM}$ mannitol, which showed that M-81E adapted poorly to the stress of $400 \mathrm{mM}$ mannitol, and this could represent a transitional phase; at higher mannitol concentrations, M-81E began to adapt to the stressinducing mannitol. After $7 \mathrm{~d}$ of water restoration, germination percentage increase of $\mathrm{M}-81 \mathrm{E}$ was higher than that of Roma (Fig. 2D), suggesting that M-81E had a stronger ability to recover. Shoot and root length of both sweet sorghum lines decreased significantly with increased mannitol concentrations; however, M-81E shoot length decreased less than that of Roma under stresses of 200 and $600 \mathrm{mM}$ mannitol (Fig. 3A), but M-81E root length decreased more than that of Roma (Fig. 3B). After $7 \mathrm{~d}$ of water restoration, shoot and root length of $\mathrm{M}-81 \mathrm{E}$ increased more than that of Roma (Fig. 3C,D); this demonstrated that the stronger ability of M-81E to recover might be related to the powerful osmotic adjustment ability to ensure establishment of seeds and seedling under different drought stresses. In order to further illustrate the drought resistances of the two sweet sorghum inbred lines, we also performed the experiment during the seedling stage.

Plants respond to water stress by closing stomata, which reduces $\mathrm{CO}_{2}$ availability in the chloroplasts,
Effect of drought stress on MDA content at seedling stage: Under drought stress, the MDA content of M-81E and Roma increased by 16.8 and $65.8 \%$, respectively; after 7-d recovery, the MDA content of M-81E decreased to normal level, while that of Roma remained high (Fig. 8). These results showed that damage of cell membranes in $\mathrm{M}-81 \mathrm{E}$ was less severe than that in Roma.

progressively decreasing photosynthesis and photosynthetic capacity (Lawlor 1995, Reddy et al. 2004, Ashraf 2013). The activities of PSII and PSI appeared to be inhibited in response to drought stress in plants such as Tuberaria major (Cistaceae) (Osório 2013), and this occurred to a greater extent in Roma compared to M-81E (Fig. 4). We also demonstrated that PSI of Roma was more sensitive to drought stress than PSII (Fig. 4). After $7 \mathrm{~d}$ of water restoration, recovery ability of $\mathrm{M}-81 \mathrm{E}$ was better than that of Roma. PSII is thought to perform a vital function in the response of leaf photosynthesis to environmental stresses (Baker 1991). The lower utilization of light energy inevitably results in an excess of light energy, and PSII consequently becomes overexcited. Our results showed that excess energy produced in Roma under drought stress resulted in accumulation of electrons at the PSI acceptor side (Inoue et al. 1989).

PSII photoinhibition is closely related to the redox state of $\mathrm{Q}_{\mathrm{A}}$ under a range of stress conditions (Havaux et al. 1991). The relative redox state of $Q_{A}$ in vivo can be estimated as $1-\mathrm{q}_{\mathrm{p}}$ (Qin et al. 2011). Results showed that $1-\mathrm{q}_{\mathrm{p}}$ in both sweet sorghum lines increased under drought stress, with a greater increase in Roma (Fig. 5A). This suggested that the extent of $\mathrm{Q}_{\mathrm{A}}$ reduction in Roma was more severe under drought stress. The increase of $1-\mathrm{q}_{\mathrm{p}}$ was accompanied by an increase in NPQ (Fig. 5B), suggesting that the extent of PSII photoinhibition correlated closely with the redox state of $\mathrm{Q}_{\mathrm{A}}(\mathrm{Xu}$ et al. 1999). Changes of $F_{0}$ depend on the dominant factor between the energy dissipation and damage to PSII. We showed that the $\mathrm{F}_{0}$ of $\mathrm{M}-81 \mathrm{E}$ increased less than that of Roma under drought treatment (Fig. 5C), which indicated that damage to PSII of Roma was greater than that of M$81 \mathrm{E}$. We found that $\Phi_{\mathrm{PSII}}$ of M-81E decreased less than that of Roma (Fig. 5D), which suggested that M-81E also had a higher photosynthetic capacity. After $7 \mathrm{~d}$ of water restoration, M-81E had a greater capacity for recovery than Roma; this suggested that under drought stress, the PSII of M-81E experienced less photoinhibition than that of Roma, and energy dissipation was effective at preventing damage to the M-81E PSII reaction center.

In this study, we observed higher shoot and root FM and DM in M-81E than in Roma under drought stress, and M-81E could recover quickly relative to Roma after rewatering for $7 \mathrm{~d}$ (Fig. 6). If excess energy in plants could not be dissipated and $\mathrm{CO}_{2}$ assimilation was blocked, PSII reaction centers were completely reduced to produce 
triplet Chl; it could easily react with singlet oxygen to generate ROS in normal metabolic processes (Asada 1992, 1999), especially under environmental stress. The resulting deficit in removal of ROS in plant cells leads to excessive accumulation of free radicals, which triggers or aggravates membrane lipid peroxidation of cells, causing damage to the plant (Fridovich 1975, Smirnoff 1993, Mehdy 1994). Meanwhile, plants contain various nonenzymatic antioxidants, such as ascorbate, glutathione, flavonoids, and carotenoids; they also contain enzymatic antioxidants, such as SOD, APX, and catalase (CAT) (Song et al. 2005). These all function to properly scavenge the toxic ROS and protect the plants from ROS damage (Noctor and Foyer 1998). Under drought stress, the activities of SOD, APX, and CAT are positively correlated with drought resistance (Jiménez and Pick 1993, Scandalios 1993). Drought-resistant varieties could maintain higher SOD, APX, and CAT activity than varieties with weaker drought resistances. SOD activity is crucial to enzymatic scavenging of active oxygen. When exposed to drought stress, the antioxidative enzyme system seemed to function better in M-81E than in Roma (Fig. 7). During drought stress, the ETC tends to form $\mathrm{O}_{2}{ }^{-}$, which could be metabolized by SOD to form $\mathrm{H}_{2} \mathrm{O}_{2}$. When exposed to drought stress, the SOD activity of M-81E was higher than that of Roma (Fig. 7A). APX, which eliminates peroxides by converting AsA to dehydroascorbate, is one of the most important enzymes for eliminating toxic $\mathrm{H}_{2} \mathrm{O}_{2}$ in plants (Foyer et al. 1994). Activities of APX increased in both sweet sorghum lines under drought stress (Fig. 7B); however, the APX activity of M-81E increased more than that of Roma under drought stress. The $\mathrm{H}_{2} \mathrm{O}_{2}$ contents of $\mathrm{M}-81 \mathrm{E}$ were consistently lower than those of Roma under

\section{References}

Agarie S., Hanaoka N., Ueno O. et al.: Effects of silicon on tolerance to water deficit and heat stress in rice plants (Oryza sativa L.), monitored by electrolyte leakage. - Plant Prod. Sci. 1: 96-103, 1998.

Ahmad S., Ahmad R., Ashraf M.Y. et al.: Sunflower (Helianthus annuus L.) response to drought stress at germination and seedling growth stages. - Pak. J. Bot. 41: 647-654, 2009.

Ahmed C.B., Rouina B.B., Sensoy S. et al.: Changes in gas exchange, proline accumulation and antioxidative enzyme activities in three olive cultivars under contrasting water availability regimes. - Environ. Exp. Bot. 67: 345-352, 2009.

Almodares A., Hadi M.R.: Production of bioethanol from sweet sorghum. - Afr. J. Agr. Res. 4: 772-780, 2009.

Anjum S.A., Xie X., Wang L. et al.: Morphological, physiological and biochemical responses of plants to drought stress. Afr. J. Agr. Res. 6: 2026-2032, 2011.

Asada K.: Ascorbate peroxidase a hydrogen peroxide scavenging enzyme in plants. - Physiol. Plantarum 85: 235241, 1992.

Asada K.: The water-water cycle in chloroplasts: scavenging of active oxygens and dissipation of excess photons. - Annu. Rev. Plant Biol. 50: 601-639, 1999.

Ashraf M., Foolad M.: Roles of glycine betaine and proline in drought stress, and it seems that $\mathrm{H}_{2} \mathrm{O}_{2}$ could not be scavenged efficiently in Roma under drought stress with the relatively lower SOD and APX activities (Fig. 7C). The higher $\mathrm{H}_{2} \mathrm{O}_{2}$ contents of Roma also enhanced photoinhibition of PSII and PSI (Fig. 4), and even damaged the PSII reaction centers. After rewatering for $7 \mathrm{~d}, \mathrm{H}_{2} \mathrm{O}_{2}$ contents decreased more quickly in $\mathrm{M}-81 \mathrm{E}$ than in Roma (Fig. 7C); this showed that when environmental conditions improve, the growth and physiological parameters of M-81E could recover more quickly than those of Roma.

Changes of cell membrane permeability in plants under stress conditions can reflect the extent of damage (Agarie et al. 1998). The strongly cytotoxic MDA is one of the main products of membrane lipid peroxidation, and the degree of damage to plants positively correlates with MDA accumulation under stress conditions, but is negatively related to drought resistance (Wang and Luo 1990, Bai et al. 2011). Antioxidant enzyme activity and MDA content could be used to identify and select drought-resistant plants (Li et al. 2008). In this study, the leaf MDA content of M-81E was lower than that of Roma under natural drought stress. After rewatering for $7 \mathrm{~d}$, leaf MDA content of M-81E decreased more significantly than that of Roma (Fig. 8). This showed that the stress-related damage to Roma was more serious, and M-81E had stronger drought resistance.

In conclusion, all the results showed that under same drought stress, M-81E had stronger recovery ability during the germination period. Compared to Roma at the seedling stage, M-81E showed stronger osmotic adjustment and more powerful antioxidative enzyme system, which ensured establishment of seeds and seedlings during drought conditions. improving plant abiotic stress resistance. - Environ. Exp. Bot. 59: 206-216, 2007.

Ashraf M., Harris P.J.C.: Photosynthesis under stressful environments: an overview. - Photosynthetica 51: 163-190, 2013.

Awika J.M., Rooney L.W.: Sorghum phytochemicals and their potential impact on human health. - Phytochemistry 65: 11991221, 2004

Bacelar E.A., Santos D.L., Moutinho-Pereira J.M. et al.: Physiological behaviour, oxidative damage and antioxidative protection of olive trees grown under different irrigation regimes. Plant Soil 292: 1-12, 2007.

Bai Z.Y., Li C.D., Zhao J.F. et al.: Effect and preliminary analysis of chromosomal control on the chlorophyll fluorescence parameters of wheat substitution lines between synthetic hexaploid wheat and Chinese spring under drought stress. - Sci. Agric. Sin. 1: 7, 2011. [In Chinese]

Baker N.R.: A possible role for photosystem II in environmental perturbations of photosynthesis. - Physiol. Plantarum 81: 563570, 1991.

Ballesteros M., Oliva J.M., Negro M.J. et al.: Ethanol from lignocellulosic materials by a simultaneous saccharification and fermentation process (SFS) with Kluyveromyces marxianus CECT 10875. - Process Biochem. 39: 1843-1848, 2004. 
Beiragi M.A., Ebrahimi M., Mostafavi K. et al.: A study of morphological basis of corn (Zea mays L.) yield under drought stress condition using correlation and path coefficient analysis. - J. Cereals Oilseeds 2: 32-37, 2011.

Bradford M.M.: A rapid and sensitive method for the quantitation of microgram quantities of protein utilizing the principle of protein-dye binding. - Anal. Biochem. 72: 248-254, 1976.

Burnett S., Thomas P., van Iersel M.: Postgermination drenches with PEG-8000 reduce growth of salvia and marigolds. HortScience 40: 675-679, 2005.

Buschmann C., Konanz S., Zhou M. et al.: Excitation kinetics of chlorophyll fluorescence during light-induced greening and establishment of photosynthetic activity of barley seedlings. Photosynthetica 51: 221-230, 2013.

Cosentino S.L.: Crop physiology of sweet sorghum (Sorghum bicolor (L.) Moench). - In: Proceedings of First European Seminar on Sorghum for Energy and Industry. Pp. 1-3. 1996.

Delachiave M.E.A., Pinho S.Z.: Germination of Senna occidentalis link: seed at different osmotic potential levels. - Braz. Arch. Biol. Techn. 46: 163-166, 2003.

Dhanda S., Sethi G., Behl R.K.: Indices of drought tolerance in wheat genotypes at early stages of plant growth. - J. Agron. Crop Sci. 190: 6-12, 2004.

Dhindsa R.S., Plumb-Dhindsa P., Thorpe T.A.: Leaf senescence: correlated with increased levels of membrane permeability and lipid peroxidation, and decreased levels of superoxide dismutase and catalase. - J. Exp. Bot. 32: 93-101, 1981.

El-Sharkawy M.A.: Prospects of photosynthetic research for increasing agricultural productivity, with emphasis on the tropical $\mathrm{C}_{4}$ Amaranthus and the cassava $\mathrm{C}_{3}-\mathrm{C}_{4}$ crops. Photosynthetica 54: 161-184, 2016.

Evans R., Skaggs R., Sneed R.: Normalized crop susceptibility factors for corn and soyabean to excess water stress. - T. ASAE 33: $1153-1161,1990$.

Farsiani A., Ghobadi M.: Effects of PEG and $\mathrm{NaCl}$ stress on two cultivars of corn (Zea mays L.) at germination and early seedling stages. - World Acad. Sci. Eng. Tech. 57: 382-385, 2009.

Foyer C.H., Lelandais M., Kunert K.J.: Photooxidative stress in plants. - Physiol. Plantarum 92: 696-717, 1994.

Fridovich I.: Superoxide dismutases. - Annu. Rev. Bioch. 44: 147-159, 1975.

Fu J., Huang B.: Involvement of antioxidants and lipid peroxidation in the adaptation of two cool-season grasses to localized drought stress. - Environ. Exp. Bot. 45: 105-114, 2001.

Gill P.K., Sharma A.D., Singh P. et al.: Osmotic stress-induced changes in germination, growth and soluble sugar content of Sorghum bicolor (L.) Moench seeds. - Bulg. J. Plant Physiol. 28: 12-25, 2002.

Golding A.J., Johnson G.N.: Down regulation of linear and activation of cyclic electron transport during drought. - Planta 218: 107-114, 2003.

Hamayun M., Sohn E.Y., Khan S.A. et al.: Silicon alleviates the adverse effects of salinity and drought stress on growth and endogenous plant growth hormones of soybean (Glycine max L.). - Pak. J. Bot. 42: 1713-1722, 2010.

Havaux M., Strasser R.J., Greppin H.: A theoretical and experimental analysis of the qp and $\mathrm{q}_{\mathrm{n}}$ coefficients of chlorophyll fluorescence quenching and their relation to photochemical and nonphotochemical events. - Photosynth. Res. 27: 41-55, 1991.

Horton P., Ruban A.V., Walters R.G.: Regulation of light harvesting in green plants (indication by nonphotochemical quenching of chlorophyll fluorescence). - Plant Physiol. 106: 415-
420, 1994.

Igartua E., Gracia M., Lasa J.: Field responses of grain sorghum to a salinity gradient. - Field Crop Res. 42: 15-25, 1995.

Inoue K., Fujii T., Yokoyama E. et al.: The photoinhibition site of photosystem I in isolated chloroplasts under extremely reducing conditions. - Plant Cell Physiol. 30: 65-71, 1989.

Jajarmi V.: Effect of water stress on germination indices in seven wheat cultivar. - World Acad. Sci. Eng. Technol. 49: 105-106, 2009.

Jiménez C., Pick U.: Differential reactivity of [beta]-carotene isomers from Dunaliella bardawil toward oxygen radicals. Plant Physiol. 101: 385-390, 1993.

Jimenez L.D., Ayer W.A., Tewari J.P.: Phytoalexins produced in the leaves of Capsella bursa-pastoris (shepherd's purse). Phytoprotection 78: 99-103, 1997.

Jordan W., Dugas W., Shouse P.: Strategies for crop improvement for drought-prone regions. - Agr. Water Manage. 7: 281299, 1983.

Kanematsu S., Asada K.: Characteristic amino acid sequences of chloroplast and cytosol isozymes of $\mathrm{CuZn}$ superoxide dismutase in spinach, rice and horsetail. - Plant Cell Physiol. 31: 99112, 1990.

Khayatnezhad M., Gholamin R., Jamaati-e-Somarin S. et al.: Effects of peg stress on corn cultivars (Zea mays L.) at germination stage. - World Appl. Sci. J. 11: 504-506, 2010.

Kozuleva M., Klenina I., Proskuryakov I. et al.: Production of superoxide in chloroplast thylakoid membranes: ESR study with cyclic hydroxylamines of different lipophilicity. - FEBS Lett. 585: 1067-1071, 2011.

Kozuleva M.A., Petrova A.A., Mamedov M.D. et al:: $\mathrm{O}_{2}$ reduction by photosystem I involves phylloquinone under steady state illumination. - FEBS Lett. 588: 4364-4368, 2014.

Lawlor, D.W.: The effects of water deficit on photosynthesis. In: Smirnoff N. (ed.): Environment and Plant Metabolism. Flexibility and Acclimation. Pp. 129-160. BIOS Sci. Publ., Oxford 1995

Lei Y., Yin C., Li C.: Differences in some morphological, physiological, and biochemical responses to drought stress in two contrasting populations of Populus przewalskii. - Physiol. Plantarum 127: 182-191, 2006.

Li X.G., Meng Q.W., Jiang G.Q., Zou Q.: The susceptibility of cucumber and sweet pepper to chilling under low irradiance is related to energy dissipation and water-water cycle. - Photosynthetica 41: 259-265, 2003.

Li Y.C., Fan W.G., Chen S.L.: Soil drought stress on membranelipid per-oxidation and antioxidant enzymes in pear rootstock. - J. Zhejiang Forestry Coll. 25: 437-441, 2008.

Mehdy M.C.: Active oxygen species in plant defense against pathogens. - Plant Physiol. 105: 467-472, 1994.

Mehler A.H.: Studies on reactions of illuminated chloroplasts: I. Mechanism of the reduction of oxygen and other hill reagents. - Arch. Biochem. Biophys. 33: 65-77, 1951.

Miyake C., Asada K.: Thylakoid-bound ascorbate peroxidase in spinach chloroplasts and photoreduction of its primary oxidation product monodehydroascorbate radicals in thylakoids. Plant Cell Physiol. 33: 541-553, 1992.

Mohammadkhani N., Heidari R.: Drought-induced accumulation of soluble sugars and proline in two maize varieties. - World Appl. Sci. J. 3: 448-453, 2008.

Mubarakshina M.M., Ivanov B.N.: The production and scavenging of reactive oxygen species in the plastoquinone pool of chloroplast thylakoid membranes. - Physiol. Plantarum 140: 103-110, 2010. 
Nakano Y., Asada K.: Spinach chloroplasts scavenge hydrogen peroxide on illumination. - Plant Cell Physiol. 21: 1295-1307, 1980.

Noctor G., Foyer C.H.: Ascorbate and glutathione: keeping active oxygen under control. - Annu. Rev. Plant Biol. 49: 249-279, 1998.

Ogbaga C.C., Stepien P., Johnson G.N.: Sorghum (Sorghum bicolor) varieties adopt strongly contrasting strategies in response to drought. - Physiol. Plantarum 152: 389-401, 2014.

Oliveira A.B., Gomes-Filho E.: Germination and vigor of sorghum seeds under water and salt stress. - Rev. Brasil. Sementes 31: 48-56, 2009.

Osório M.L., Osório J., Romano A.: Photosynthesis, energy partitioning, and metabolic adjustments of the endangered Cistaceae species Tuberaria major under high temperature and drought. - Photosynthetica 51: 75-84, 2013.

Ozkur O., Ozdemir F., Bor M. et al.: Physiochemical and antioxidant responses of the perennial xerophyte Capparis ovata Desf. to drought. - Environ. Exp. Bot. 66: 487-492, 2009.

Peever T.L., Higgins V.J.: Electrolyte leakage, lipoxygenase, and lipid peroxidation induced in tomato leaf tissue by specific and nonspecific elicitors from Cladosporium fulvum. - Plant Physiol. 90: 867-875, 1989.

Plaut Z., Federman E.: Simple procedure to overcome polyethy lene glycol toxicity on whole plants. - Plant Physiol. 79: 559561,1985

Qin L.Q., Li L., Bi C. et al.: Damaging mechanisms of chillingand salt stress to Arachis hypogaea L. leaves. - Photosynthetica 49: 37-42, 2011.

Reddy A.R., Chaitanya K.V., Vivekanandan M.: Droughtinduced responses of photosynthesis and antioxidant metabolism in higher plants. - J. Plant Physiol. 161: 11891202, 2004.

Ren C.G., Li X., Liu X.L. et al.: 1-butanol regulating the stomatal movementthrough endogenous $\mathrm{H}_{2} \mathrm{O}_{2}$ in $\mathrm{C}_{4}$ pepc transgenic rice (Oryza sativa L.). - Plant Physiol. Bioch. 74: 218-229, 2014.

Rooney W.L., Blumenthal J., Bean B. et al.: Designing sorghum as a dedicated bioenergy feedstock. - Biofuel. Bioprod. Bioref. 1: 147-157, 2007.

Sairam R., Srivastava G.: Changes in antioxidant activity in subcellular fractions of tolerant and susceptible wheat genotypes in response to long term salt stress. - Plant Sci. 162: 897-904, 2002.

Scandalios J.G.: Oxygen stress and superoxide dismutases. Plant Physiol. 101: 7, 1993.

Schansker G., Srivastava A., Govindjee, Strasser R.J.: Characterization of the $820-\mathrm{nm}$ transmission signal paralleling the chlorophyll $a$ fluorescence rise (OJIP) in pea leaves. - Funct. Plant Biol. 30: 785-796, 2003.

Schreiber U., Bilger W., Neubauer C.: Chlorophyll fluorescence as a nonintrusive indicator for rapid assessment of in vivo photosynthesis. - In: Schulze E.D., Caldwell M.M. (ed.): Ecophysiology of Photosynthesis, Vol. 100. Pp. 49-70, Springer, Dordrecht 1994.

Slama I., Ghnaya T., Hessini K. et al.: Comparative study of the effects of mannitol and PEG osmotic stress on growth and solute accumulation in Sesuvium portulacastrum. - Environ. Exp. Bot. 61: 10-17, 2007.

Smirnoff N.: The role of active oxygen in the response of plants to water deficit and desiccation. - New Phytol. 125: 27-58, 1993.

Song X.S., Hu W.H., Mao W.H. et al.: Response of ascorbate peroxidase isoenzymes and ascorbate regeneration system to abiotic stresses in Cucumis sativus L. - Plant Physiol. Bioch. 43: 1082-1088, 2005.

Sui N.: Photoinhibition of Suaeda salsa to chilling stress is related to energy dissipation and water-water cycle. Photosynthetica 53: 207-212, 2015.

Taylor A., Motes J., Kirkham M.: Germination and seedling growth characteristics of three tomato species affected by water deficits [Lycopersicon chilense, Lycopersicon esculentum, Solanum pennellii]. - J. Am. Soc. Hortic. Sci. 107: 282-285, 1982.

Terzi R., Kadioglu A.: Drought stress tolerance and the antioxidant enzyme system. - Acta Biol. Cracov. Bot. 48: 8996, 2006.

van Kooten O., Snel J.F.: The use of chlorophyll fluorescence nomenclature in plant stress physiology. - Photosynth. Res. 25: $147-150,1990$

Wang A.G., Luo G.H.: Quantitative relation between the reaction of hydroxylamine and superoxide anion radicals in plants. Plant Physiol. Commun. 6: 55-57, 1990.

$\mathrm{Xu}$ C.C., Jeon Y.A., Lee C.H.: Relative contributions of photochemical and non photochemical routes to excitation energy dissipation in rice and barley illuminated at a chilling temperature. - Physiol. Plantarum 107: 447-453, 1999.

Yu J., Tuinstra M., Claassen M. et al.: Analysis of cold tolerance in sorghum under controlled environment conditions. - Field Crop. Res. 85: 21-30, 2004.

Zavariyan A.M., Rad M.Y., Asghari M.: Effect of seed priming by pyridoxine on germination and biochemical indices in Silybum marianum L. under drought stress. - Int. J. Life Sci. 9: $17-22,2015$ 